\title{
Healthcare waste management in Greece. The example of Health Region of Western Greece, Peloponnese, Epirus and Ionian Islands
}

\author{
Zamparas M.1,* and Kalavrouziotis I. ${ }^{2}$ \\ ${ }^{1} 6$ th Region of Healthcare: Peloponnese, Epirus, Ionian Islands and Western Greece, Ipatis 1, 26441, Patras, Greece \\ ${ }^{2}$ Hellenic Open University, School of Science and Technology, Parodos Aristotelous 18, 26335, Patras, Greece \\ Received: 05/05/2017, Accepted: 25/08/2017, Available online: 06/12/2017 \\ *to whom all correspondence should be addressed. e-mail: mzamparas@upatras.gr
}

\begin{abstract}
The aim of the present study is a) to examine the healthcare waste management practices in W. Greece, Peloponnese, Epirus and Ionian islands b) to investigate the implementation of the institutional frame and c) to make suggestions in order to achieve a proper Hospital Healthcare Waste Management utilizing best practices. A questionnaire was prepared and distributed to selected people in 29 hospitals. The survey was conducted in the period 2015-2016.
\end{abstract}

The results showed that more hospitals have an established Hazardous Medical Waste Management System, based on internal regulation of infectious waste management. The quantities of infectious wastes produced by the studied hospitals, expressed per day and bed ( $\mathrm{kg}$ bed -1 day -1 ) were within the range illustrated both in Greek and International literature. In relation to waste management policy, the replies to the questionnaire show that most attention is given to the management of hazardous medical wastes, while the necessary importance is not given in the appropriate management of urban wastes (separation, recycling and reuse). In addition, according to the findings of the present study, the wastewater management in hospitals is considered of minor importance.

Thus, more investigation is required to evaluate the best operation wastewater treatment scheme to achieve the protection of human health and ecosystems.

The hospitals studied have not tried to adopt an Ecological Management and Audit Scheme (EMAS) a fact that reinforces our observation that none of them had made a commitment to minimize the environmental impact related to their function.

Keywords: healthcare waste, waste Management

\section{Abbreviations}

HCW - Healthcare Waste

HCWF - Commander of Healthcare Waste Facilities

HCWM - Healthcare Waste Management

HWPC - Hazardous Waste Purely Contagious
HWSU - Hazardous Waste from Sanitary Units

JMD - Joint Ministerial Decision

MHW - Mixed Hazardous Waste

SU - Sanitary Units

SWS - Specific Waste streams

USW - Urban Solid Waste

\section{Introduction}

In recent years the environmental dimension is considered as an extremely important parameter, which should be taken into account during the procedure of regional planning and development.

The new doctrine is to secure the development of sustainability, which is based on the fundamental ecological principles of solidarity between generations, and resource renewal. Thus, based on this evidence, the understanding of the waste management and especially of medical waste management is by all means significant in an effort to achieve the desirable sustainable development.

Approximately $75-90 \%$ of Healthcare Waste (HCW) are considered non-hazardous (that is similar to household waste), while the remaining $10-25 \%$ are considered dangerous, with the possibility of causing contamination to anyone who is exposed to them. (EEDSA, 2006).

Healthcare Waste (HCW) and by-products cover a diverse range of materials, as the following list illustrates (EEDSA, 2006):

infectious waste: waste contaminated with blood and other bodily fluids (e.g. from discarded diagnostic samples), cultures and stocks of infectious agents from laboratory work (e.g. waste from autopsies and infected animals from laboratories), or waste from patients in isolation wardsand equipment (e.g. swabs, bandages and disposable medical devices).

pathological waste: human tissues, organs or fluids, body parts and contaminated animal carcasses;

sharps: syringes, needles, disposable scalpels and blades, etc. 
chemicals: for example, solvents used for laboratory preparations, disinfectants, and heavy metals contained in medical devices (e.g. mercury in broken thermometers) and batteries.

pharmaceuticals: expired, unused and contaminated drugs and vaccines.

genotoxicwaste: highly hazardous, mutagenic, teratogenic or carcinogenic, such as cytotoxic drugs used in cancer treatment and their metabolites.

radioactive waste: such as products contaminated by radionuclides including radioactive diagnostic material or radiotherapeutic materials.

High-income countries generate on average up to $0.5 \mathrm{~kg}$ of hazardous waste per bed per day; while low-income countries generate on average $0.2 \mathrm{~kg}$. However, healthcare waste is often not separated into hazardous or nonhazardous wastes in low-income countries making the real quantity of hazardous waste much higher (Altin, 2003; Eker and Bilgili 2011; WHO, 2015).

Investigations showed that waste production depends on many factors including; a) the established methods of healthcare waste management, b) the type of healthcare facilities, c) the number and kind of medical specialties, d) the proportion of reusable items used in health care and e) the proportion of patients per therapeutic care day (Prüss et al., 1999).

\section{Health risks}

Health-care waste contains potentially harmful microorganisms which can infect hospital patients, health workers and the general public. Other potential infectious risks may include the spread of drug-resistant microorganisms from health facilities into the environment.

Health risks associated with waste and by-products also include:

-radiation burns

-sharps-inflicted injuries

-poisoning and pollution through the release of pharmaceutical products, in particular, antibiotics and cytotoxic drugs

-poisoning and pollution through waste water; and by toxic elements or compounds such as mercury or dioxins that are released during incineration (WHO, 2015).

Inappropriate collection and separation of Healthcare Waste, results in increased cost of treatment, since infectious or toxic waste can be also mixed with urban-type waste. This is mainly due to the lack of awareness and proper training of employees on the collection of such waste The above factors make very difficult the evaluation of HCW approximate quantities (Tsakona et al., 2007). Moreover, direct contact with the Healthcare Waste, or indirect contact through the food chain (hazardous substances enter via soil or ground water) poses potential health risk (Salkin, 2004).
It has been shown that separation of healthcare waste at the source in three separate containers, is a practical and cost-effective method, which when appropriately applied, drastically reduces the main risks (Health Care Waste, 2001-2013b). More specifically, small bins of different colour are placed in specific rooms inside the hospital in order to enable the personnel to dispose the different waste fractions at suitable places. For example, the red bins are used for the infectious waste collection, while the black ones are used for the municipal waste collection. Special plastic bins for the collection of syringes and sharps are also used. This is very advantageous, since sharps and especially syringes represent a great threat for the personnel and public health (Mousiopoulos et al., 2002).

In 1992 United Nations conference, Agenda 21 was adopted. The following recommendations for healthcare waste management were proposed: 1) Prevent and minimize waste production, 2) Reuse and recycle waste, 3) Treatment of waste with safe methods, 4) Deposition of them in landfills residues. The first step towards the implementation of the aforementioned Agenda is to conduct research on the site of waste production, focusing on the kind and the quantities of different types of waste. This is an imperative requirement before any specific plans aiming at the reduction of the waste generation and waste reuse and recycling are developed (Prüss et al., 1999). According to $\mathrm{WHO}$, the route that healthcare waste follow can be separated into 8 steps (Health Care Waste, 2001$2013 b)$, the first one being minimization of their generation with appropriate planning, before they are produced. Such a division can be proven useful for the more efficient planning of the management of hazardous waste. Collection of HCW should be organised in bags or other type of containers in the most suitable form for the treatment method to be followed; for example: the HCW for sterilization should be placed in yellow bags, for incineration in red bags and sharps in a puncture- resistant, autoclave, hard, plastic containers. The temporary storage of $\mathrm{HCW}$, in SU, should be done in specially designed spaces, of adequate capacity and under conditions where there is no risk of deterioration of waste (Greek Governmental Gazette B1537/8-5-2012). The transport of healthcare waste is made either by the sanitary unit or by a specialized company, which has been contracted by the hospital. Drivers and operators must be appropriately trained and should be familiar with the type of waste and the risks posed by them (Prüss et al., 1999). The most prevalent method of treatment for most dangerous HCW is incineration. It is a process used for waste that cannot be recycled or reused or disposed of in suitable disposal facilities. In regard to the health care management method the WHO suggests that the countries must conduct assessment before choosing the respective management method. Also suggest that the government Organizations adopt a strategy suitable for the particular conditions of each country. The suggested strategy could be (a) Short term, (b) medium term and (c) Long term strategies.

It is obvious the fact that the effective medical health care waste management greatly depends of the number of 
health care units, the number of beds, the primary health care units, Multi peripheral medical centers etc. The following statistics about the Health Care System in Greece is given below:

The total number of hospital beds in Greece reaches up to 57000, according to data collected in 2014. In Greece the following public health care units are operating (Bakopoulou et al., 2006):

- 97 public hospitals with 37.000 beds and 1700 special care units

- 204 primary health centres

- Multi-unit peripheral medical centres, diagnostic centres, medical research centres etc.

Table 1. Production rate of healthcare waste of different countries.

\begin{tabular}{ccc}
\hline Countries & Production rate (Kg day-1 patient-1) & References \\
\hline Spain & 0.6 & \\
\hline Portugal & 1.5 & Krisiunas et al., 2000, \\
\hline Holland & 0.6 & Chung and Lo, 2003 \\
\hline Italy & 1.0 & Tudor et al., 2008 \\
\hline Gernany & 0.4 & \\
\hline Greece & 1.4 & \\
\hline
\end{tabular}

However, there are numerous private care units such as private clinics, private medical practices, dental practices, private diagnostic centres and private multi-unit medical centres.

The official report for hazardous wastes production in Greece for the year 2008 (report from the Ministry of Environment), for the health sector is 133.000 tons of hospital waste that can be analysed as follows:

- 115.000 tons of Non hazardous or general health care waste

- 14.000 tons of infectious wastes

- $\quad 3.500$ tons of mixed (toxic plus infectious wastes)

In the present work the current status of 29 hospital units in the 6th Region of Health has been studied. The basic aim of the present work is associated with the issues raised above, and more specifically with the collection, treatment and management of dangerous infectious wastes (HCWs).

\section{Materials and Methods}

An appropriate questionnaire was prepared and distributed to selected people in 29 hospitals. The survey was conducted in the period 2015-2016. The questionnaire was addressed to the managers responsible for healthcare waste management of the hospital and to selected white Staff members from each unit. More specifically, the questionnaires were addressed to the following categories of white Staff: Public health supervisors, nurse in charge of surveillance of infections, health visitor, clinical supervisor, supervisor of surgery and head of technical services. All questionnaires were completed through a personal interview. The survey was conducted through personal interviews in order to gain better, well justified by facts, answers. The interviews were held in many categories of the Staff in order to see whether they were up to date on the relevant to their duties issues of hospital healthcare waste management and whether they implemented them appropriately. In this manner, the results reported here are more reliable as they were validated by facts, examples provided by the interviewers and cross examination of given answers. In addition, the information collected was more detailed than it would have been if the questionnaires were anonymous without any personal interview sessions. The questionnaire included 25 questions, covering the following topics: General descriptive information (6 questions), production of infectious waste ( 2 questions), waste management ( 8 questions), waste management costs (1 question) personnel training on the management of waste (4 questions) workers safety related directly to the management ( 2 questions) and management legislation (2 questions).

\section{Results}

Figure 1 shows the average composition of the hazardous characteristics of hospital wastes that have been studied in 29 hospitals of 6th Health Region of Western Greece, Peloponnese, Epirus and Ionian Islands was: General waste $82 \%$, Infectious waste $13 \%$, Toxic (chemical, pharmaceuticals) $4 \%$, Others $1 \%$.

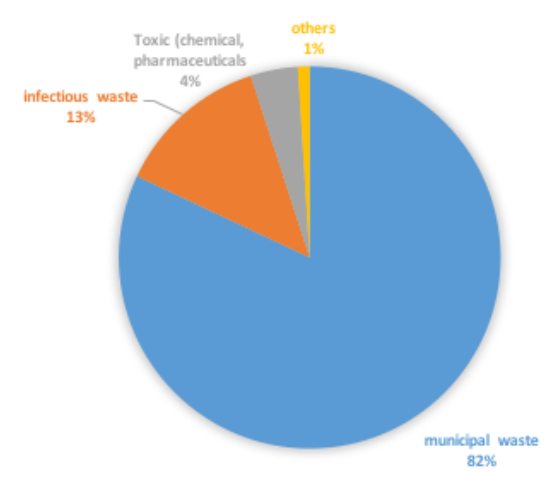

Figure 1. Average percent distribution of the general, infectious (hazardous) and other non-infectious wastes produced by the hospitals, studied.

Waste produced by health-care providers is comparable to domestic waste and usually called "non-hazardous" or "general health-care waste". It comes mostly from the administrative, kitchen and housekeeping functions at health-care facilities and may also include packaging waste and waste generated during maintenance of health-care buildings. 
Moreover, Figure 2 represents the average composition of urban solid waste in the studied health units. It is obvious that almost $50 \%$ refers to the paper. In total, the characteristics of urban waste produced in the health care activities have been classified as follows: Paper 47\%, Plastic18\%, Metals 9\%, Food remains (organics) $16 \%$ Glass $8 \%$, and Wood $2 \%$.

Also, the results of this study showed that eighteen, of a total of 27 hospitals, have an established Hazardous Medical Waste Management System, based on internal regulation of infectious waste management (Table 2).

It is observed that the values emerged from this study were within the range illustrated in the literature (Ananth et al., 2010; Blenkarn, 2006; $\mathrm{MOH}, 2009$ ) and in the upper limit of the range. The wastewater management practices in contrast to the management of solid waste create concern. The fact that there is no control of the characteristics of waste water-particularly the wastewaters from labs to determine if they meet the entry requirements in wastewater treatment plants, is a significant omission in any case, the need to minimize the volume of waste generated by applying recycling techniques, is important.

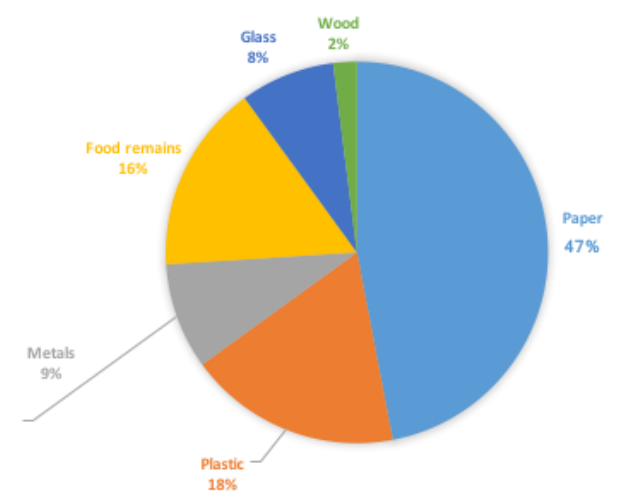

Figure 2. Average distribution of the urban characteristics of hospital solid wastes (paper, plastics, metals, food remains (organics), glass, and wood).

Table 2. Hospitals and established Hazardous Medical Waste Management System ( $\mathrm{Y}=\mathrm{Yes}, \mathrm{N}=\mathrm{No}$ ) and Production of urban waste per sanitary unit. Produced quantity is expressed as $\mathrm{kg} \mathrm{day}^{-1}$ per bed.

\begin{tabular}{|c|c|c|c|c|}
\hline & HOSPITALS & (a) HMWS & $\begin{array}{c}\text { (b) URBAN } \\
\text { (Kg day-1bed-1) }\end{array}$ & $\overbrace{\text { EMAS }}$ \\
\hline \multirow{9}{*}{$\begin{array}{l}\text { WESTERN } \\
\text { GREECE }\end{array}$} & 1. General hospital of Agrinio & $\mathrm{Y}$ & 2.14 & $\mathrm{~N}$ \\
\hline & 2. General hospital of Mesolongi & $\mathrm{N}$ & 1.19 & $\mathrm{~N}$ \\
\hline & 3. General hospital of Patras & $\mathrm{Y}$ & 4.16 & $\mathrm{~N}$ \\
\hline & 4. University Hospital of Patras (Rio) & $\mathrm{Y}$ & 5.72 & $\mathrm{~N}$ \\
\hline & 5. General Hospital of Pyrgos & $\mathrm{Y}$ & 2.68 & $\mathrm{~N}$ \\
\hline & 6. General Hospital of Amaliada & $\mathrm{N}$ & 1.07 & $\mathrm{~N}$ \\
\hline & 7. General Hospital of Krestena & $\mathrm{N}$ & 0.73 & $\mathrm{~N}$ \\
\hline & 8. Pediatric Hospital Karamandanio & $\mathrm{Y}$ & 1.21 & $\mathrm{~N}$ \\
\hline & 9. General Hospital of Aigio & $\mathrm{Y}$ & 2.46 & $\mathrm{~N}$ \\
\hline \multirow{5}{*}{$\begin{array}{l}\text { IONIAN } \\
\text { ISLANDS }\end{array}$} & 10. General Hospital of Zakynthos & $\mathrm{N}$ & 1.11 & $\mathrm{~N}$ \\
\hline & 11. General Hospital of Corfu & $\mathrm{Y}$ & 2.47 & $\mathrm{~N}$ \\
\hline & 12. General Hospital of Lefkada & $\mathrm{N}$ & 1.29 & $\mathrm{~N}$ \\
\hline & 13. General Hospital of Kefallonia (Argostoli) & $\mathrm{Y}$ & 0.72 & $\mathrm{~N}$ \\
\hline & $\begin{array}{l}\text { 14. General Hospital of Kefallonia } \\
\text { (Mantzavinatio) }\end{array}$ & $\mathrm{N}$ & 0.57 & $\mathrm{~N}$ \\
\hline \multirow{5}{*}{ EIPIRUS } & 15. General Hospital of Arta & $\mathrm{Y}$ & 2.24 & $\mathrm{~N}$ \\
\hline & 16. General Hospital of Preveza & $\mathrm{N}$ & 1.19 & $\mathrm{~N}$ \\
\hline & 17. University Hospital of Ioannina & $\mathrm{Y}$ & 4.61 & $\mathrm{~N}$ \\
\hline & 18. General Hospital of Filiates & $\mathrm{Y}$ & 1.34 & $\mathrm{~N}$ \\
\hline & 19. General Hospital of Ioannina & $\mathrm{Y}$ & 3.41 & $\mathrm{~N}$ \\
\hline \multirow{8}{*}{ PELOPONNESE } & 20. General Hospital of Argos & $\mathrm{Y}$ & 1.72 & $\mathrm{~N}$ \\
\hline & 21. General Hospital of Nafplio & $\mathrm{Y}$ & 1.21 & $\mathrm{~N}$ \\
\hline & 22. General Hospital of Tripoli & $\mathrm{Y}$ & 2.22 & $\mathrm{~N}$ \\
\hline & 23. General Hospital Of Sparti & $\mathrm{N}$ & 1.82 & $\mathrm{~N}$ \\
\hline & 24. Genaral Hospital of Molaoi & $\mathrm{N}$ & 0.93 & $\mathrm{~N}$ \\
\hline & 25. General Hospital of Kalamata & $\mathrm{Y}$ & 2.22 & $\mathrm{~N}$ \\
\hline & 26. General Hospital of Kyparissia & $\mathrm{Y}$ & 1.66 & $\mathrm{~N}$ \\
\hline & 27. General Hospital of Korinthos & $\mathrm{Y}$ & 1.64 & $\mathrm{~N}$ \\
\hline
\end{tabular}


Observing the answers of the questionnaires and correlating them with the quantities of waste generated in each hospital, we can see that all personnel dealing with health-care waste were familiar with the main categories of health-care waste as set out in either national or local regulations on waste classification. As a minimum, managers responsible for health-care waste had the knowledge of the facility to identify the medical areas that produce waste, obtaining a minimum estimate of the types and quantities of waste generated, and to understand how the waste is handled and disposed of.

Beyond the minimal requirements, eighteen, of a total of 27 health-care facilities adopt an organized approach to waste characterization to obtain accurate data. This approach is necessary to develop or improve the waste management system in use. Undertaking a formal waste assessment entails planning and preparation. This systematic assessment identifies locations in the healthcare facility where good waste segregation is undertaken and where segregation practices need to be improved. In addition, this approach determines the potential for recycling and other waste-minimization measures and also estimate the quantities of hazardous health-care waste that require special handling.

The results showed that a larger health-care facility (University Hospital of Patras and University hospital of loannina) has established a formal waste-management plan. This document contains the combined knowledge and decisions for all involved in the production, handling and treatment of wastes. A senior person at a health-care facility chosen and made responsible for preparing the plan, collecting ideas from others and, once agreed, promoting the way health-care waste should be managed to medical and ancillary staff. In large establishments, the structure includes a specialist hospital hygienist, in addition to, or instead of, the infection-control officer, to address persistent difficulties relating to hospital hygiene, such as persistent methicillin-resistant Staphylococcus aureus or Clostridium difficile contamination.

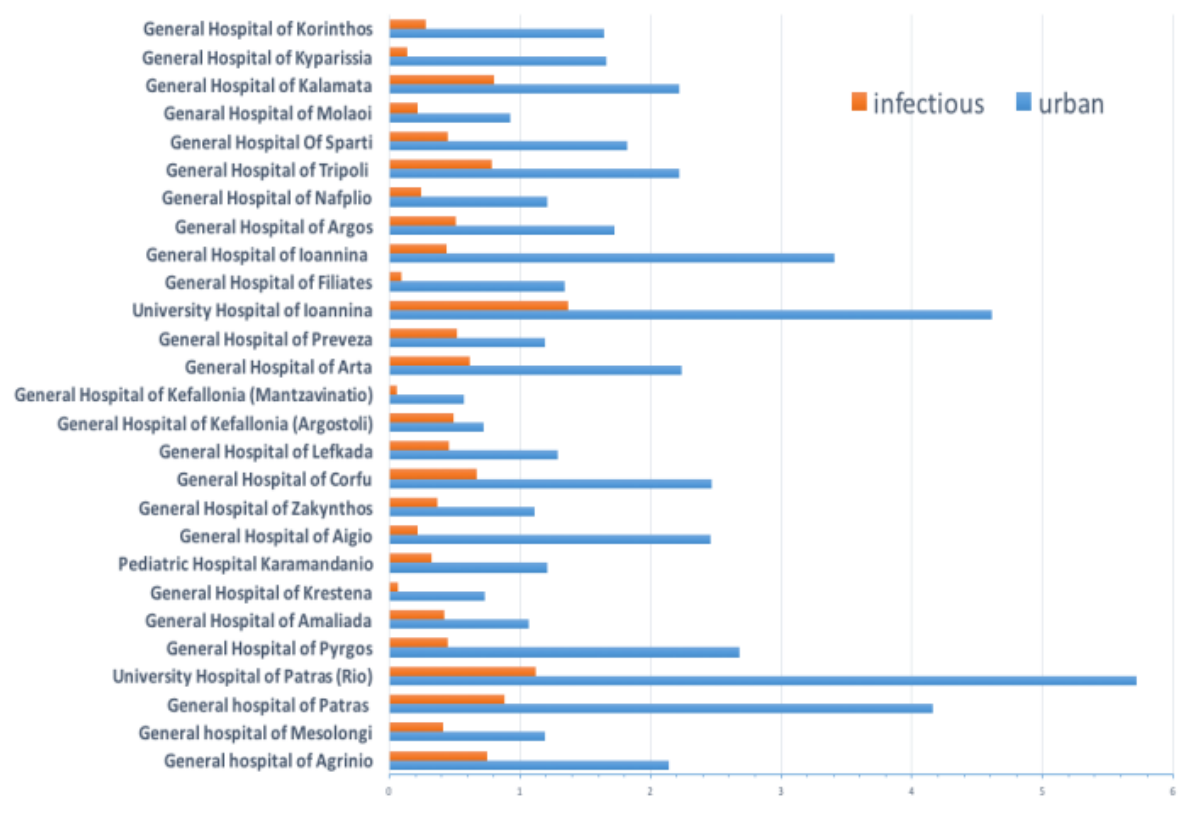

Figure 3. Production of infectious and urban waste per sanitary unit. Produced quantity (kg day ${ }^{-1}$ per bed). Orange bars indicate infectious waste and blue bars urban waste

In all hospitals, medical waste was separated in fractions similar to household waste in Urban Solid Waste (USW) and also in Hazardous Waste from Sanitary Units (HWSU) close to the site of production, as defined by JMD 146163/2012 "Measures and Terms on the Waste Management from Sanitary Units" (Governmental Gazette B1537/8-5-2012). However, the respondents often remarked that due to momentum, occasional errors in waste separation did occur. Sometimes they occurred by mistake during the separation process; in other occasions, the lack of awareness and understanding of various management issues related to the environmental protection and health was to be blamed for. As such, in all cases where the separation waste was not correct, hazardous waste contaminated the USW rendering them hazardous too, thus, unnecessarily increasing the quantity of the final HWSU. However, the latter cause of errors was not reported as a key problem and it was thought that it could be easily resolved through periodical training and by appropriately scheduled updating of training of the Staff involved (Table 3). Moreover, the medical Urban Solid Waste (USW), that are similar to the household waste, were collected in black plastic bags in all hospitals studied. According to the JMD (Governmental Gazette B1537/8-52012), Hazardous Waste Purely Contagious (HWPC) must be placed in containers of yellow or red color depending on the final processing. So, the HWPC which are going to be sterilized, should be placed in yellow bags and then in yellow boxes, while those HWPC intended for incineration, must be placed in red bags, and then in red boxes (Table 3 ). 
The process of Collection was more adequate and more comprehensive than separation (Table 3).

The treatment method followed by all hospitals, for HWPC, is sterilization, which takes place in the town of Volos, in mainland Greece by the Joint Stock company "Sterilization S.A.". In addition, the method of treatment of the Mixed Hazardous Waste (MHW) at all hospitals was incineration. This is carried out in ESDKNA in Athens, the capital of Greece (Table 3).

Table 3. Evaluation of management process in 29 hospitals of $6^{\text {th }}$ Health Region of Western Greece, Peloponnese, Epirus and Ionian Islands. • good $\bullet$ medium $\bullet$ poor

\begin{tabular}{|c|c|c|c|c|c|c|}
\hline & $\begin{array}{c}\text { HOSPITALS } \\
\end{array}$ & Segregation & Collection & Treatment & Labelling & Minimisation \\
\hline \multirow{9}{*}{ 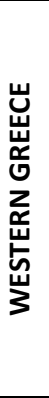 } & 1. General hospital of Agrinio & $\bullet$ & $\bullet$ & sterilization & $\bullet$ & $\cdot$ \\
\hline & 2. General hospital of Mesolongi & $\cdot$ & $\cdot$ & sterilization & $\cdot$ & 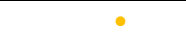 \\
\hline & 3. General hospital of Patras & - & - & sterilization & 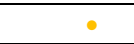 & 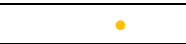 \\
\hline & $\begin{array}{l}\text { 4. University Hospital of Patras } \\
\text { (Rio) }\end{array}$ & - & - & sterilization & - & - \\
\hline & 5. General Hospital of Pyrgos & 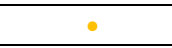 & $\bullet$ & sterilization & $\bullet$ & $\circ$ \\
\hline & 6. General Hospital of Amaliada & $\cdot$ & $\cdot$ & sterilization & $\cdot$ & $\bullet$ \\
\hline & 7. General Hospital of Krestena & - & $\bullet$ & sterilization & $\cdot$ & $\cdot$ \\
\hline & 8. Pediatric Hospital Karamandanio & $\cdot$ & $\cdot$ & sterilization & 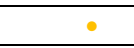 & $\circ$ \\
\hline & 9. General Hospital of Aigio & $\bullet$ & $\bullet$ & sterilization & 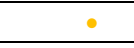 & $\circ$ \\
\hline \multirow{5}{*}{ 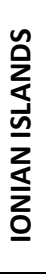 } & 10. General Hospital of Zakynthos & $\bullet$ & $\bullet$ & sterilization & $\circ$ & $\circ$ \\
\hline & 11. General Hospital of Corfu & $\bullet$ & $\bullet$ & sterilization & $\bullet$ & $\circ$ \\
\hline & 12. General Hospital of Lefkada & $\cdot$ & $\bullet$ & sterilization & $\cdot$ & $\cdot$ \\
\hline & $\begin{array}{l}\text { 13. General Hospital of Kefallonia } \\
\text { (Argostoli) }\end{array}$ & - & $\bullet$ & sterilization & 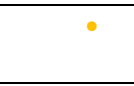 & $\bullet$ \\
\hline & $\begin{array}{l}\text { 14. General Hospital of Kefallonia } \\
\text { (Mantzavinatio) }\end{array}$ & $\bullet$ & $\cdot$ & sterilization & 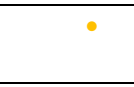 & $\cdot$ \\
\hline \multirow{5}{*}{ 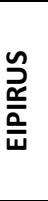 } & 15. General Hospital of Arta & $\bullet$ & $\bullet$ & sterilization & 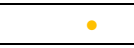 & $\cdot$ \\
\hline & 16. General Hospital of Preveza & $\cdot$ & $\bullet$ & sterilization & $\cdot$ & $\bullet$ \\
\hline & 17. University Hospital of Ioannina & $\bullet$ & $\cdot$ & sterilization & $\bullet$ & $\bullet$ \\
\hline & 18. General Hospital of Filiates & $\bullet$ & $\bullet$ & sterilization & $\circ$ & $\bullet$ \\
\hline & 19. General Hospital of Ioannina & $\bullet$ & $\bullet$ & sterilization & $\bullet$ & $\cdot$ \\
\hline \multirow{8}{*}{ 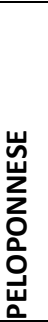 } & 20. General Hospital of Argos & $\cdot$ & $\bullet$ & sterilization & $\circ$ & $\circ$ \\
\hline & 21. General Hospital of Nafplio & 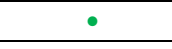 & $\bullet$ & sterilization & $\cdot$ & $\circ$ \\
\hline & 22. General Hospital of Tripoli & $\cdot$ & $\cdot$ & sterilization & $\cdot$ & $\cdot$ \\
\hline & 23. General Hospital Of Sparti & $\cdot$ & $\cdot$ & sterilization & 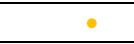 & $\bullet$ \\
\hline & 24. Genaral Hospital of Molaoi & $\bullet$ & $\bullet$ & sterilization & + & $\bullet$ \\
\hline & 25. General Hospital of Kalamata & $\bullet$ & $\bullet$ & sterilization & $\bullet$ & $\cdot$ \\
\hline & 26. General Hospital of Kyparissia & $\cdot$ & $\bullet$ & sterilization & $\cdot$ & $\circ$ \\
\hline & 27. General Hospital of Korinthos & $\bullet$ & $\cdot$ & sterilization & $\cdot$ & $\cdot$ \\
\hline
\end{tabular}

The recycling of the HCW programs were applied in all hospitals (Table 3). More specifically, all hospitals performed recycling of paper in cooperation with the municipality to which they belong. Furthermore, the large University hospitals carried out recycling of plastic, of lubricating oils, of printer inks (toners) and of all types of light bulbs. However, recycling is not done in a permanent and organized manner. Is therefore an issue that needs to be expanded and guaranteed in all hospitals and not just in the large sanitary units (SU).

According to the JMD [Governmental Gazette B1537/8-52012] all packaging waste should be labeled with the basic information about their content and production details. Specifically, it must have an embedded waterproof label written by permanent ink, and bear the international symbol and the corresponding labeling of infectious and / or hazardous waste (according to the UN class in which the waste has been classified). Furthermore, the term "hazardous waste", must be clearly displayed, as well as the class and the UN number for their risk. Finally, date of production and packaging of the waste, the precise location of production (chamber / section / lab), quantity and destination of the waste must be indicated. Unfortunately, in all of the hospitals studied, the labeling of the contained material was frequently insufficient for the receptors. More specifically:

None of the hospital units mentioned the existence of embedded waterproof labels by indelible ink.

-All three hospitals indicated clearly the term "Hazardous Waste".

-University Hospital of Patras, General Hospital of Corfu, General Hospital of Pyrgos, General Hospital of Agrinio, General Hospital of Kalamata and University Hospital of loannina mentioned the indication of class and UN number as to their risk.

-Although in all units wastes were being labelled, only University Hospital of Patras was fully consistent as specifically is defined by the JMD (Governmental Gazette B1537/8-5-2012). 


\section{Conclusions and suggestions}

In this study, the medical waste management in Greece and more specifically in Health Region of Western Greece, Peloponnese, Epirus and Ionian Islands was examined. Our main conclusion is that the problem of medical waste management in must be faced with greater interest by the Administration due to its health and environmental impact. Attention must be paid to the more efficient training of the personnel, More systematic and effective application of the guidelines as they have been set both by the Greek state, and the WHO, governing the handling of the infectious wastes, application of more effective methods of treatment and proper segregation of the wastes produced. At national level, the Greek Ministry of Health should develop clear plans and policies for the proper management and disposal of wastes. Education and training of hospital personnel is also significant, in order to assure that these plans will be put into practice. The establishment of a system of continuous controls in the Greek hospitals for the assurance of the implementation of the above plans is significant as well. Finally, difficulties may arise in the implementation of the National and European Community legislation during the management of the infectious wastes, related to cost, training of white staff involved, and security measures to be taken. According to Kamitsou et al. (2015) deviations have been reported for Greek hospitals of Mytilini, Agrinion and Messolonghi, which were recognised as serious difficulties in the implementation of the legislation throughout the process i.e. from separation to the phase of processing, primarily originating from limited financing.

Focussing to our results, we can conclude that the quantities of infectious wastes, produced by the studied hospitals, expressed per day and bed $\left(\mathrm{kg} \mathrm{bed}^{-1}\right.$ day $\left.^{-1}\right)$ (Table1\& Table2) were within the range illustrated both in Greek and International literature indicating good practices in hazardous medical waste management (Figure 3). For example, the infectious wastes produced by the $\mathrm{H} /$ day/bed and $0,945 /$ day $/$ bed, respectively, and $0.085 \mathrm{~kg} /$ day $/$ bed for Messolonghi (Kamitsou et al. 2015).

In relation to waste management policy, the replies to the questionnaire show that most attention is given to the management of hazardous medical wastes, while the necessary importance is not given in the appropriate management of urban wastes (separation, recycling and reuse). Finally, hospital units studied in this work had no commitment to minimize the environmental impact related to their function. The fact that no hospital has tried to adopt an Ecological Management and Audit Scheme (EMAS) reinforced this conclusion.

\section{References}

Altin S. (2003), Determination of hospital waste composition and disposal methods: a case study, Polish Journal of Environmental Studies, 12(2), 251-255.

Ananth A.P., Prshanthini V. and Visvanathan C. (2010), Healthcare Waste Management in Asia, Waste Management and Research, 30, 154-161.
Bakopoulou S., Kougolos A. and Arabosis K. (2006), Regional Hospital Waste Management Planning As a mean of determining the required investments: The case of Thessaly Region. 2nd international conference of the Hellenic Solid Waste Management Association, e - proceedings, February 3 - 4, Athens, Greece.

Blenkarn I.J. (2006), Standards of Clinical Waste Management in UK Hospitals, Journal of Hospital Infection, 62, 303-303.

EEDSA (2006), http://www.eedsa.gr/ Cont ents.aspx?Catld=125, in Greek.

Eker H.H. and Bilgili M.S. (2011), Statistical analysis of waste generation in healthcare services: a case study, Waste Manag. Res., 29, 791-796.

Governmental Gazette B 1537/8-5-2012, Joint Ministerial Decision 146163/2012 "Measures and Terms on the Waste Management from Sanitary Units", (in Greek). Available at: http://www.elinyae.gr/el/lib_ file_upload/1537b_12.13372 52766296.pdf

Health Care Waste (2001-2013b), http:// www.healthcarewaste.org/basics/risk-reduct ion/.

Kamitsou A., Kalavrouziotis I.K. and Papadaki M. (2015), Healthcare Waste Management Planning of Hospitals in the Prefectures of Aetoloakarnania and the Island of Lesbos, Greece, Global Nest Journal, 17(2), 312-322.

Komilis D. and Katsafaros N. (2011), Statistical predictors of hazardous medical waste generation rates in a 40-bed general hospital, Global NEST Journal, 13, 170-175. (this reference is not in the text)

$\mathrm{MOH}$. (2009). Project Operation Guidelines for Clinical Waste Management Services: Privatised Hospital Support Services Ministry of Health Malaysia. (Document No. POG/CWMS/C01), Putrajaya, Malaysia: SIHAT.

Mousiopoulos N.and Karagiannidis A. (2002), "Notes on lesson of Waste Management", Thessaloniki, pp 4, (in Greek) Available at: http://aix.meng.auth.gr/lhtee/education/swm1.pdf, (accessed February 2013).

Prüss A., Giroult E. and Rushbrook P. (1999), "Safe management of wastes from health-care activities", World Health Organization, Geneva.

Salkin I.F. (2004). "Review of Health Impacts from Microbiological Hazards in Health-Care Wastes", Department of Blood Safety and Clinical Technology and Department of Protection of the Human Environment World Health Organization, Geneva. Available at: http://www.who.int/water_sanitation_ health/medicalwaste/en/microbhazards0306.pdf.

Tsakona M., Anagnostopoulou E. and Gidarakos E. (2007), Hospital waste management and toxicity evaluation: A case study, Waste Manag., 27(7), 912-20.

WHO (2015). Water, sanitation and hygiene in health care facilities: status in low- and middle-income countries. World Health Organization, Geneva. 